Review

\title{
Impact of age at diagnosis in polymyalgia rheumatica: A retrospective cohort study of 218 patients
}

\author{
Maarten Van Hemelen ${ }^{\mathrm{a}, 1}$, Albrecht Betrains ${ }^{\mathrm{a}, \mathrm{b}, 1}$, Steven Vanderschueren ${ }^{\mathrm{a}, \mathrm{b}}$, \\ Daniel Blockmans ${ }^{\text {a, b, * }}$ \\ ${ }^{a}$ Department of General Internal Medicine, University Hospitals Leuven, Herestraat 49, 3000 Leuven, Belgium \\ ${ }^{\mathrm{b}}$ Laboratory of Clinical Infectious and Inflammatory Disease, Department of Microbiology, Immunology and Transplantation, KU Leuven, Herestraat 49 , 3000 Leuven, \\ Belgium
}

\section{A R T I C L E I N F O}

\section{Keywords:}

Polymyalgia rheumatica

Age

Relapse

Glucocorticoids

\begin{abstract}
A B S T R A C T
Background: Polymyalgia rheumatica (PMR) is a common musculoskeletal inflammatory disease that may occur with giant-cell arteritis (GCA) or in an isolated form. While the incidence is highest in the elderly, there is a paucity of data on its presentation, clinical course and response to treatment in younger individuals. Methods: We conducted a retrospective review of 40 patients who were diagnosed with isolated PMR under the age of 60 and 178 patients diagnosed above this age, taking into account clinical and laboratory data and treatment history.

Results: Patients who were diagnosed at a younger age had lower acute-phase reactant levels at diagnosis but not after initiation of treatment or at the time of relapse. The risk of relapse was lower in the group diagnosed under age 60 (35\% vs 55\%). Cumulative and maximal glucocorticoid doses, use of glucocorticoid-sparing agents and duration of glucocorticoid treatment, did not differ between the groups. In multivariate analysis, younger age at diagnosis was associated with cervical pain and male gender.

Conclusion: Compared to patients diagnosed above age 60, patients diagnosed with PMR at a younger age have a lower risk of relapse, but similar long-term outcomes with regards to continued need for treatment.
\end{abstract}

\section{Introduction}

Polymyalgia rheumatica (PMR) is a common inflammatory disorder that usually presents in patients over 50 years of age, characterised by girdle pain in the shoulders and hips, cervical or lumbar spine pain, morning stiffness, and increased inflammatory parameters that often respond promptly to treatment with glucocorticoids [1]. The clinical course is variable however, and around half of patients suffer relapses, requiring re-intensified treatment which exposes patients to the significant risks of long-term glucocorticoid use [2-4]. PMR may be found as an isolated phenomenon or in association with giant cell arteritis (GCA) [5].

In other rheumatic diseases, including ANCA-associated vasculitis and rheumatoid arthritis, age may have a significant impact on the clinical phenotype, prognosis, or response to treatment [6-8]. Delaval et al. recently conducted a retrospective study in GCA patients aged between 50 and 60 years at onset and compared them to GCA patients aged over 60 years [9], finding differences in presentation (predominantly large-vessel involvement versus cranial disease) and more refractory disease in younger patients.

In 2018, Charpentier et al. analyzed a cohort of 42 patients with PMR, comparing 14 patients aged between 50 and 60 years at onset to patients aged over 60 years [10]. They found that young patients with PMR were mostly men and were more dependent on corticosteroids compared to elderly patients. Prior research on factors determining timing of relapses, had not identified age as a significant factor [3]. To further elucidate the role of age in the clinical presentation, laboratory findings, disease course, and treatment response of polymyalgia rheumatica, we conducted a retrospective analysis of 218 patients with isolated PMR.

\footnotetext{
* Corresponding author at: Department of general internal medicine, University Hospitals Leuven, Herestraat 49, 3000 Leuven, Belgium.

E-mail addresses: maarten.vanhemelen@uzleuven.be (M. Van Hemelen), albrecht.betrains@student.kuleuven.be (A. Betrains), steven.vanderschueren@uzleuven. be (S. Vanderschueren), daniel.blockmans@uzleuven.be (D. Blockmans).

1 These authors contributed equally to this work.
} 


\section{Methods}

\subsection{Patients}

We collected data from a local registry of patients diagnosed with polymyalgia rheumatica from January 2000 through December 2017 in the outpatient clinic or hospitalisation unit of the General Internal Medicine department of the University Hospitals of Leuven, Leuven, Belgium. Patients were eligible for inclusion if they were newly diagnosed with isolated PMR during this time period. The diagnosis of isolated PMR was based on the judgment of an experienced clinician (DB and SV) after a 6-month follow-up period, taking into account all available information (clinical data and evolution, biochemical, radiological, and PET results).

In our centre, the standard treatment for PMR consists of $15 \mathrm{mg}$ prednisone equivalent/day as starting dose for 4 weeks, followed by $10 \mathrm{mg} /$ day for 6 weeks, $7.5 \mathrm{mg} /$ day for 6 weeks, $5 \mathrm{mg} /$ day for 8 weeks, $2.5 \mathrm{mg} /$ day for another 8 weeks, after which treatment is discontinued if no relapses occur. Hence, the total treatment duration typically lasts 32 weeks in uncomplicated cases. The standard follow-up is organised 2 weeks after the initial diagnosis, 4 weeks after the first dose reduction, and every 3 months thereafter for 32 weeks with extra visits for relapses or adverse events. After 32 weeks, the follow up interval may vary between 3 and 6 months. However, both treatment duration and follow-up may be adjusted on an individual basis.

We excluded patients with evidence of giant-cell arteritis at the time of the initial presentation; patients who developed GCA after initial remission of PMR were not excluded. Patients were also excluded if a likely alternative diagnosis explained their symptoms, either at presentation or later in the course of their illness, or in case of features of systemic illness that were not well explained by PMR. Patients were also excluded if they were receiving glucocorticoid treatment for another diagnosis. Patients with distal symptoms, including remitting seronegative symmetric synovitis and pitting edema (RS3PE-syndrome), were not excluded as this is deemed to be a variant presentation of the same spectrum as polymyalgia rheumatica [11-14].

This study was approved by the Ethical Research Committee of the University Hospitals of Leuven, Belgium. Informed consent was waived because of the retrospective nature of the study and the analysis used anonymised clinical data.

\subsection{Data collection}

For each patient, we collected the following clinical data from the Electronic Health Record if available: manifestations at disease onset including fever, anorexia/weight loss, shoulder girdle pain, hip girdle pain, cervical and lumbar spine pain; presence and duration of morning stiffness; comorbidity (GCA and RS3PE); time until disease control; presence and timing of relapse(s).

Relapse was defined as need for a restart or an increase of the dose of glucocorticoids, or addition of a glucocorticoid-sparing agent, in patients who had earlier had clinical improvement on treatment.

We determined maximal doses of glucocorticoids as well as cumulative doses at one and three months (expressed as milligrams of prednisone equivalent). Use of glucocorticoid-sparing agents was also noted. Laboratory data included presence of rheumatoid factor or anticitrullinated cyclic polypeptide antibodies, as well as erythrocyte sedimentation rate and blood levels of haemoglobin, and CRP at diagnosis, at follow-up visit and at the time of first relapse, if any.

\subsection{Analysis}

Data are presented as the mean \pm standard deviation (SD) or as the median and interquartile range, as appropriate, for continuous variables and frequency (percentage) for categorical variables. Quantitative variables were compared using Student's $t$-test or nonparametric tests
(Mann-Whitney $U$ test, or Wilcoxon signed rank test, as appropriate) and categorical variables were compared using Fisher's exact test or the chisquare test. Multivariable analysis was performed using a logistic regression. We included characteristics that differed between the groups with $p<0.30$. All analyses were performed using the SPSS software (version 26, IBM corp.). All statistical tests were two-sided, and significance was set at the 0.05 level.

\section{Results}

From 304 patient records screened, we identified 270 patients with PMR and excluded 29 patients with a likely alternative diagnosis (Fig. 1). After exclusions, a total of 218 patients with isolated PMR were included in the final analysis. Ninety-seven patients had complete data to allow classification by the ACR/EULAR criteria. Of these 97 patients, $62(66 \%)$ met classification criteria.

In the final cohort, 40 patients were diagnosed at an age of 60 years old or younger (the $\mathrm{PMR}_{\leq 60}$ group), and 178 were diagnosed above this age (the $\mathrm{PMR}_{>60}$ group). In the $\mathrm{PMR}_{\leq 60}$ group, $53 \%$ of patients with complete data met the ACR/EULAR classification criteria, as compared to $70 \%$ of patients in the $\mathrm{PMR}_{>60}$ group $(p=0.66)$.

\subsection{Clinical, laboratory and imaging characteristics}

Table 1 shows the presenting characteristics of our patient cohort, stratified by age at diagnosis. The median age at diagnosis was 55 (IQR 49-57) for the $\mathrm{PMR}_{\leq 60}$ group, and 72 (IQR 67-77) for the $\mathrm{PMR}_{>60}$ group. The youngest age at diagnosis in the cohort was 44 years old, while the eldest was $88.40 \%$ of the $\mathrm{PMR}_{\leq 60}$ patients were female, compared to $57 \%$ of the $\mathrm{PMR}_{>60}$ group, a trend that fell short of significance $(p=0.05)$.

In the $\mathrm{PMR}_{\leq 60}$ group, $55 \%$ presented with isolated musculoskeletal complaints, in the absence of any systemic symptoms, while anorexia or weight loss were noted in $27 \%$ and fever in $17 \%$. Most patients had shoulder (90\%) and hip (80\%) pain, while pain at the cervical and lumbar spinal level were documented for $32 \%$ and $20 \%$, respectively. Morning stiffness was noted in $70 \%$. None of these characteristics were significantly different from the $\mathrm{PMR}_{>60}$ group.

Compared to the $\mathrm{PMR}_{>60}$ group, those in the $\mathrm{PMR}_{\leq 60}$ group had significantly lower absolute values of CRP (median of $36.5 \mathrm{v} 49.6 \mathrm{mg} / \mathrm{L}$; $p=0.02$ ) and ESR (median of $42.5 \mathrm{v} 56.0 \mathrm{~mm} / \mathrm{h} ; p=0.005$ ), and higher haemoglobin levels (median of $13.0 \mathrm{v} 12.0 \mathrm{~g} / \mathrm{dL} ; p=0.01$ ) at diagnosis. After initiation of treatment, and at the time of first relapse, these differences were no longer detectable. A statistically significant difference in ESR remained after initiating treatment. $15 \%$ of patients in the $\mathrm{PMR}_{\leq 60}$ group, and $14 \%$ of those in the $\mathrm{PMR}_{>60}$ group, had only lowgrade biochemical signs of inflammation (CRP $\leq 10 \mathrm{mg} / \mathrm{L}$ ) at diagnosis $(p=1)$.

We conducted multivariate analysis to identify any clinical characteristics that are independently associated with younger age at presentation. As shown in Table 2, patients in the $\mathrm{PMR}_{\leq 60}$ group were less likely to be female (OR $0.47 ; p=0.03$ ) and more likely to report pain in the cervical region (OR $2.49 ; p=0.04$ ). No other characteristics reached statistical significance.

\subsection{Treatment and clinical course}

All of the patients in the $\mathrm{PMR}_{\leq 60}$ group and 175/178 patients in the $\mathrm{PMR}_{>60}$ group received first-line treatment with glucocorticoids; in the $\mathrm{PMR}_{>60}$ group, 2 patients with mild symptoms were managed symptomatically and 1 patient had an initial spontaneous remission, but did receive glucocorticoids later for a relapse.

Treatment regimens and outcomes are summarised in Table 3. In patients with sufficient data to calculate cumulative doses, the cumulative prednisone equivalent dose at 28 days was $460 \mathrm{mg}$ (IQR 420-560 $\mathrm{mg}$ ) in the $\mathrm{PMR}_{\leq 60}$ group and $420 \mathrm{mg}$ (IQR 415-525 mg) in the $\mathrm{PMR}_{>60}$ 


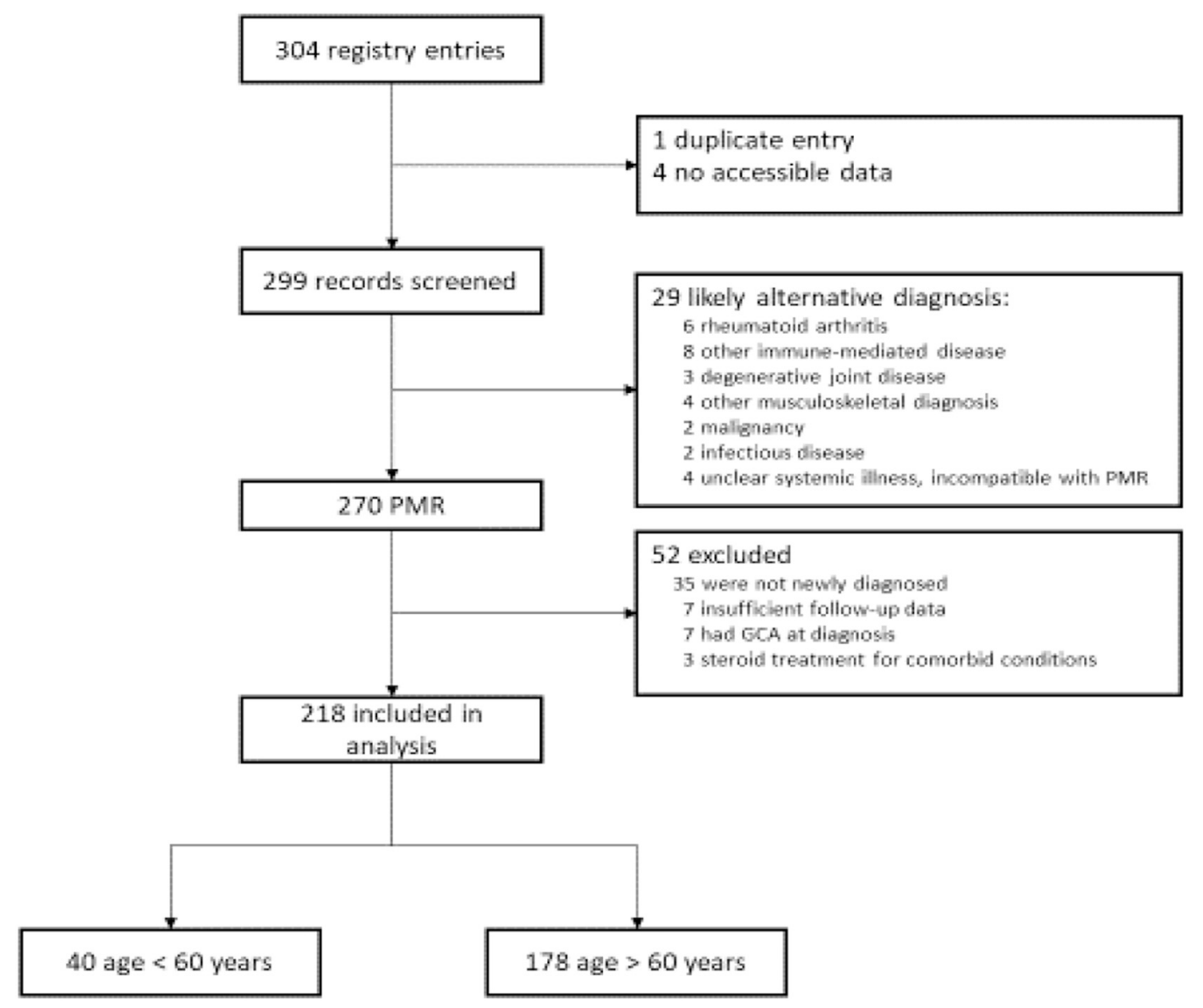

Fig. 1. Inclusion process.

Table 1

Clinical and laboratory characteristics.

\begin{tabular}{|c|c|c|c|}
\hline Characteristics & $\begin{array}{l}\mathrm{PMR}_{\leq 60}(n= \\
40)\end{array}$ & $\begin{array}{l}\mathrm{PMR}_{>60}(n= \\
178)\end{array}$ & $\begin{array}{l}P \text { - } \\
\text { value }\end{array}$ \\
\hline \multicolumn{4}{|l|}{ Demographics } \\
\hline Female & $16(40 \%)$ & $101(57 \%)$ & 0.05 \\
\hline Age at diagnosis & $55(49-57)$ & $72(67-77)$ & - \\
\hline \multicolumn{4}{|l|}{ Clinical manifestations } \\
\hline $\begin{array}{l}\text { Isolated musculoskeletal } \\
\text { symptoms }\end{array}$ & $22(55 \%)$ & $106(60 \%)$ & 0.79 \\
\hline Fever & $7(17 \%)$ & $20(11 \%)$ & 0.29 \\
\hline Anorexia or weight loss & $11(27 \%)$ & $62(35 \%)$ & 0.46 \\
\hline Morning stiffness & $28(70 \%)$ & $109(61 \%)$ & 0.29 \\
\hline Shoulder girdle pain & $36(90 \%)$ & $166(93 \%)$ & 0.50 \\
\hline Cervical spine pain & $13(32 \%)$ & $33(18 \%)$ & 0.05 \\
\hline Lumbar spine pain & $8(20 \%)$ & $35(20 \%)$ & 1 \\
\hline Hip girdle pain & $32(80 \%)$ & $145(81 \%)$ & 0.82 \\
\hline \multicolumn{4}{|l|}{ Laboratory values at diagnosis } \\
\hline $\mathrm{CRP}(\mathrm{mg} / \mathrm{L})$ & $\begin{array}{l}36.5 \\
(21.0-61.6)\end{array}$ & $49.6(19.9-48.5)$ & 0.02 \\
\hline ESR $(\mathrm{mm} / \mathrm{h})$ & $\begin{array}{l}42.5 \\
(29.5-57.5)\end{array}$ & $56(40.0-81.0)$ & 0.005 \\
\hline Haemoglobin $(\mathrm{g} / \mathrm{dL})$ & $13(12.6-14.0)$ & $12(10.9-13)$ & 0.01 \\
\hline Patients with $\mathrm{CRP} \leq 10 \mathrm{mg} / \mathrm{L}$ & $6(15 \%)$ & $25(14 \%)$ & 1 \\
\hline
\end{tabular}

PMR, polymyalgia rheumatica; n, number; IQR, interquartile range; CRP, Creactive protein; ESR, erythrocyte sedimentation rate. Continuous variables are given as the median, with the first and third quartiles given in brackets.

group. At 86 months cumulative doses had risen to $1152.5 \mathrm{mg}$ (IQR 980-1265 mg) for the $\mathrm{PMR}_{\leq 60}$ group and $1050 \mathrm{mg}$ (IQR 953.75-1187.5 $\mathrm{mg}$ ) for the $\mathrm{PMR}_{>60}$ group. Differences between the groups were not statistically significant.
Table 2

Factors associated with PMR $\leq 60$ in multivariate analysis.

\begin{tabular}{llll}
\hline & OR & CI 95\% & $P$-value \\
\hline Female gender & 0.47 & $0.23-0.96$ & 0.04 \\
Fever & 2.25 & $0.83-6.13$ & 0.11 \\
Morning stiffness & 1.30 & $0.60-2.82$ & 0.50 \\
Cervical spine pain & 2.49 & $1.12-5.54$ & 0.03 \\
\hline
\end{tabular}

OR, Odds ratio; CI, Confidence intervals.

Compared to $\mathrm{PMR}_{>60}$ patients, those in the $\mathrm{PMR}_{\leq 60}$ group were less likely to relapse after their initial treatment ( 35 vs $55 \% ; p=0.02$ ). $57 \%$ of $\mathrm{PMR}_{\leq 60}$ patients who relapsed, did so within a year after starting treatment, a similar proportion to the $\mathrm{PMR}_{>60}$ group $(53 \% ; p=1)$. There was a nonsignificant trend toward less frequent diagnosis of GCA at the time of a relapse for the $\mathrm{PMR}_{\leq 60}$ group $\left(10 \%\right.$ of $\mathrm{PMR}_{\leq 60}$ patients, versus $24 \%$ of $\mathrm{PMR}_{>60}$ patients, $p=0.06$ ).

Of the PMR $\leq 60$ patients, $15 \%$ were treated with glucocorticoids for less than a year, $64 \%$ for $1-4$ years and $21 \%$ had not been able to discontinue glucocorticoids after more than 4 years of treatment, a similar distribution to the $\mathrm{PMR}_{>60}$ group. Glucocorticoid-sparing agents were used in $15 \%$ of the $\mathrm{PMR}_{\leq 60}$ group and $14 \%$ of the $\mathrm{PMR}_{>60}$ group ( $p=$ 0.81 ). Methotrexate and azathioprine were the predominantly used agents in both groups. None of the patients in the $\mathrm{PMR}_{\leq 60}$ group required more than 1 glucocorticoid-sparing agent to be used, as compared with $3 \%$ of those in the $\mathrm{PMR}_{>60}$ group; this difference was not statistically significant $(p=0.59)$. One patient in the $\mathrm{PMR}_{>60}$ group received tocilizumab as a third glucocorticoid-sparing agent.

PMR, polymyalgia rheumatica; GCA, giant-cell arteritis; RS3PE, remitting seronegative symmetrical synovitis with pitting edema. 
Table 3

Management and clinical course.

\begin{tabular}{|c|c|c|c|}
\hline Characteristics & $\begin{array}{l}\mathrm{PMR}_{\leq 60}(n= \\
40)\end{array}$ & $\begin{array}{l}\mathrm{PMR}_{>60}(n= \\
178)\end{array}$ & $\begin{array}{l}P \text { - } \\
\text { value }\end{array}$ \\
\hline \multicolumn{4}{|l|}{ Glucocorticoid treatment } \\
\hline Cumulative dose 28 days & $\begin{array}{l}460(420-560) \\
n=38\end{array}$ & $\begin{array}{l}420(415-525) \\
n=171\end{array}$ & 0.19 \\
\hline Cumulative dose 86 days & $\begin{array}{l}1153 \\
(980-1265) \\
n=37\end{array}$ & $\begin{array}{l}1050 \\
(954-1188) \\
n=165\end{array}$ & 0.29 \\
\hline Maximal dose & $20(15-20)$ & $20(15-20)$ & 0.5 \\
\hline \multicolumn{4}{|l|}{ Treatment duration } \\
\hline$\leq 12$ months & $5(15)$ & $17(12)$ & 0.62 \\
\hline $12-47$ months & $21(64)$ & $93(65)$ & 0.84 \\
\hline$\geq 48$ months & $7(21)$ & $32(23)$ & 1 \\
\hline \multicolumn{4}{|l|}{ Effect on acute phase reactants } \\
\hline $\begin{array}{l}\text { CRP, after initiating therapy } \\
(\mathrm{mg} / \mathrm{L})\end{array}$ & $1.4(1.0-6.4)$ & $3.9(1.3-8.7)$ & 0.26 \\
\hline $\mathrm{CRP}$, at first relapse (mg/L) & $9.2(2.0-31.7)$ & $15.4(8.0-26.0)$ & 0.36 \\
\hline $\begin{array}{l}\text { ESR, after initiating therapy } \\
(\mathrm{mm} / \mathrm{h})\end{array}$ & $10(7.0-16.0)$ & $16(8.0-30.0)$ & 0.04 \\
\hline ESR, at first relapse $(\mathrm{mm} / \mathrm{h})$ & $13.5(7.8-27.3)$ & $27(14.3-40.0)$ & 0.13 \\
\hline \multicolumn{4}{|l|}{ Relapse } \\
\hline Total & $14(35)$ & $98(55)$ & 0.02 \\
\hline Early ( $\leq 1$ year) & $8(57)$ & $52(53)$ & 1 \\
\hline \multicolumn{4}{|l|}{ Comorbidity } \\
\hline GCA diagnosis at relapse & $4(10)$ & $51(24)$ & 0.06 \\
\hline RS3PE & $2(5)$ & $16(9)$ & 0.75 \\
\hline \multicolumn{4}{|l|}{ Glucocorticoid-sparing agents } \\
\hline 2nd-line & $6(15)$ & $25(14)$ & 0.81 \\
\hline methotrexate & 5 & 13 & \\
\hline azathioprine & 1 & 10 & \\
\hline hydroxychloroquine & 0 & 1 & \\
\hline cyclophosphamide & 0 & 1 & \\
\hline 3rd-line & $0(0)$ & $5(3)$ & 0.59 \\
\hline azathioprine & 0 & 3 & \\
\hline methotrexate & 0 & 2 & \\
\hline 4th-line & $0(0)$ & $1(0.6)$ & 1 \\
\hline tocilizumab & 0 & 1 & \\
\hline
\end{tabular}

Glucocorticoid doses are expressed as mg of prednisone equivalent.

\section{Discussion}

To our knowledge, our study is the largest retrospective analysis to date to determine the impact of age on the clinical presentation, laboratory findings, disease course, and treatment response in patients with isolated polymyalgia rheumatica.

The retrospective analysis of 42 patients with PMR by Charpentier et al. described individuals with PMR of 60 years or younger as a different subset of patients. Sixty-five percent of these patients were men in contrast to recent epidemiological studies reporting 64\% of PMR cases occurring in women $[10,15]$. We can confirm that more patients tended to be male in our $\mathrm{PMR}_{\leq 60}$ group. Patients in the $\mathrm{PMR}_{\leq 60}$ group also tended to present more often with inflammatory pain in the cervical region compared to the $\mathrm{PMR}_{>60}$ group. Both findings were statistically significant in multivariate analysis but not in univariate analysis. Future research is needed to confirm whether true differences in presentation, based on age, exist.

The young PMR patients in the retrospective analysis by Charpentier et al. were also significantly more often dependent on corticosteroids [10]. However, our study results do not provide evidence for a more severe presentation in patients diagnosed at a younger age. Patients with isolated PMR in the $\mathrm{PMR}_{\leq 60}$ group and the PMR $>60$ group received similar courses of glucocorticoids for a similar total duration, irrespective of age. In addition, the highest dose of corticosteroids required to achieve disease control throughout the entire treatment duration as well as the need for glucocorticoid-sparing agents did not differ significantly between the groups.

We found the risk of disease relapse to be slightly higher in the $\mathrm{PMR}>60$ group. Serum acute-phase reactants at diagnosis were also higher in this group. The clinical relevance of this finding is unclear, as the total duration of treatment was not impacted by the difference in relapse risk, and differences in CRP remitted after initiation of treatment. Prior research has shown persistently raised CRP after initiation of treatment to be a more powerful prognostic marker than raised acute phase reactants at diagnosis [4].

Our study has several strengths. Primarily, we examined a relatively large sample of patients with isolated PMR (218 in total). The exclusion of patients with associated GCA at diagnosis precludes age-dependent presentations of GCA [9] confounding the data. In addition, multiple outcomes pertaining to disease severity (relapse likelihood and timing, maximal and cumulative doses of glucocorticoids, need for glucocorticoid-sparing agents, and total duration of glucocorticoid treatment) were recorded, to allow for the possibility that more aggressive treatment of younger patients masked a more severe presentation of the disease.

There are also several limitations to our study. First, retrospective studies are of course inherently subject to variation in the completeness of data. This design also precludes adjusting for unanticipated confounding factors. Second, the limited sample size of the $\mathrm{PMR}_{\leq 60}$ group implies a lack of power to find more subtle differences between the groups. As our study spans two decades, there may also be some heterogeneity within the groups, as understanding of the disease and its treatments evolved over time. Finally, the findings from our singlecentre study may be difficult to generalise to a broader population.

A significant percentage of included patients in our retrospective cohort were not classifiable by EULAR/ACR criteria for PMR. Twentyfive percent of $\mathrm{PMR}_{\leq 60}$ patients were systematically excluded from classification as they were younger than 50 years old at disease onset. Rheumatoid factor and anti-cyclic citrullinated polypeptide antibody tests are not routinely obtained in patients with typical disease manifestations of PMR in our centre, and the quality of recorded data for leg pain and duration of morning stiffness varies. As the EULAR/ACR criteria were published in 2012, many of our patients were diagnosed before their dissemination. Furthermore, the EULAR/ACR criteria have been found to have varying sensitivity for PMR in different cohorts [16-18], and are designed for classification rather than diagnostic purposes. In the patients that were classifiable, we found a similar proportion to meet criteria as in the original validation cohort [16]. Our patient cohort and study results emphasise that the diagnosis of PMR should not systematically be disregarded because of a younger patient age at diagnosis - particularly as the disease course appears to be very similar between younger and older patients.

Likewise we can contrast our findings with similar research in giant cell arteritis. PMR and GCA frequently occur together, and there is discussion whether they are part of a spectrum, or two distinct but frequently co-occurring diseases [19]. Apart from their frequent cooccurrence, PET evidence suggests that limited large vessel vasculitis may occur in patients with isolated PMR [20], and histologically normal temporal artery biopsies have shown similarities in cytokine profile between GCA and isolated PMR [21]. A minority of patients with isolated PMR subsequently develops GCA, which may occur years later and despite glucocorticoid therapy [22,23]. Patients diagnosed with GCA at a younger age appear to have a more severe clinical course, with a phenotype that includes predominantly large vessel involvement, a higher risk of aortic complications and more frequent need for intensification of immunosuppression, as compared to older patients who more often develop cranial disease [9]. Interestingly however, presence of PMR symptoms in patients with GCA does not differ based on age.

In summary, our study suggests that isolated PMR is a relatively homogeneous disease with respect to age. Pending further research, more aggressive treatment for younger patients is not warranted.

\section{Disclosures}

All authors report no conflicts of interest. 


\section{Funding}

None.

\section{References}

[1] Salvarani C, Gabriel SE, Michael O'Fallon W, Hunder GG. Epidemiology of polymyalgia rheumatica in Olmsted County, Minnesota, 1970-1991. Arthritis Rheum 1995;38:369-73. https://doi.org/10.1002/art.1780380311.

[2] Gabriel SE, Sunku J, Salvarani C, O'Fallon WM, Hunder GG. Adverse outcomes of antiinflammatory therapy among patients with polymyalgia rheumatica. Arthritis Rheum 1997;40:1873-8. https://doi.org/10.1002/art.1780401022.

[3] Kremers HM, Reinalda MS, Crowson CS, Zinsmeister AR, Hunder GG, Gabriel SE. Relapse in a population based cohort of patients with polymyalgia rheumatica. J Rheumatol 2005;32:65-73.

[4] Salvarani C, Cantini F, Niccoli L, Macchioni P, Consonni D, Bajocchi G, et al. Acutephase reactants and the risk of relapse/recurrence in polymyalgia rheumatica: a prospective followup study. Arthritis Care Res 2005;53:33-8. https://doi.org/ 10.1002/art.20901.

[5] Weyand CM, Goronzy JJ. Giant-cell arteritis and polymyalgia rheumatica. N Engl J Med 2014;371:50-7. https://doi.org/10.1056/NEJMcp1214825.

[6] Krams T, Ruyssen-Witrand A, Nigon D, Degboe Y, Tobon G, Fautrel B, et al. Effect of age at rheumatoid arthritis onset on clinical, radiographic, and functional outcomes: the ESPOIR cohort. Jt Bone Spine 2016;83:511-5. https://doi.org/ 10.1016/j.jbspin.2015.09.010.

[7] Booth AD, Almond MK, Burns A, Ellis P, Gaskin G, Neild GH, et al. Outcome of ANCA-associated renal vasculitis: a 5-year retrospective study. Am J Kidney Dis 2003;41:776-84. https://doi.org/10.1016/S0272-6386(03)00025-8.

[8] Van Schaardenburg D, Hazes JMW, De Boer A, Zwinderman AH, Meijers KAE, Breedveld FC. Outcome of rheumatoid arthritis in relation to age and rheumatoid factor at diagnosis. J Rheumatol 1993;20:45-52.

[9] Delaval L, Daumas A, Samson M, Ebbo M, De Boysson H, Liozon E, et al. Largevessel vasculitis diagnosed between 50 and 60 years: case-control study based on 183 cases and 183 controls aged over 60 years. Autoimmun Rev 2019;18:714-20. https://doi.org/10.1016/j.autrev.2019.05.008.

[10] Charpentier A, Verhoeven F, Sondag M, Guillot X, Prati C, Wendling D. Therapeutic response to prednisone in relation to age in polymyalgia rheumatica: a comparison study. Clin Rheumatol 2018;37:819-23. https://doi.org/10.1007/s10067-0183988-3.

[11] Salvarani C, Cantini F, Macchioni P, Oliveiri I, Niccoli L, Padula A, et al. Distal musculoskeletal manifestations in polymyalgia rheumatica: a prospective followup study. Arthritis Rheum 1998;41:1221-6. https://doi.org/10.1002/1529-0131 (199807)41:7<1221::AID-ART12>3.0.CO;2-W.
[12] Salvarani C, Cantini F, Olivieri I. Distal musculoskeletal manifestations in polymyalgia rheumatica. Clin Exp Rheumatol 2000;18:S51-2. https://doi.org/ 10.1002/1529-0131(199807)41:7<1221::AID-ART12>3.0.CO;2-W.

[13] Ceccato F, Roverano SG, Papasidero S, Barrionuevo A, Rillo OL, Paira SO. Peripheral musculoskeletal manifestations in polymyalgia rheumatica. J Clin Rheumatol 2006;12:167-71. https://doi.org/10.1097/01.rhu.0000231381.21179. e6.

[14] Myklebust G. Gran JT. A prospective study of 287 patients with polymyalgia rheumatica and temporal arteritis: clinical and laboratory manifestations at onset of disease and at the time of diagnosis. Br J Rheumatol 1996;35:1161-8. https:// doi.org/10.1016/s0002-9394(14)71107-9.

[15] Raheel S, Shbeeb I, Crowson CS, Matteson EL. Epidemiology of polymyalgia rheumatica 2000-2014 and examination of incidence and survival trends over 45 years: a population-based study. Arthritis Care Res 2017;69:1282-5. https://doi. org/10.1002/acr.23132.

[16] Dasgupta B, Cimmino MA, Maradit-Kremers H, Schmidt WA, Schirmer M, Salvarani C, et al. Provisional classification criteria for polymyalgia rheumatica: a European league against rheumatism/American College of Rheumatology collaborative initiative. Ann Rheum Dis 2012;71:484-92. https://doi.org/ 10.1136/annrheumdis-2011-200329.

[17] Ozen G, Inanc N, Unal AU, Bas S, Kimyon G, Kisacik B, et al. Assessment of the new 2012 EULAR/ACR clinical classification criteria for polymyalgia rheumatica: a prospective multicenter study. J Rheumatol 2016;43:893-900. https://doi.org/ 10.3899/jrheum.151103.

[18] Macchioni P, Boiardi L, Catanoso M, Pazzola G, Salvarani C. Performance of the new 2012 EULAR/ACR classification criteria for polymyalgia rheumatica: comparison with the previous criteria in a single-Centre study. Ann Rheum Dis 2014;73:1190-3. https://doi.org/10.1136/annrheumdis-2013-204167.

[19] Salvarani C, Cantini F, Hunder GG. Polymyalgia rheumatica and giant-cell arteritis. Lancet 2008;372:234-45. https://doi.org/10.1016/S0140-6736(08)61077-6.

[20] Blockmans D, De Ceuninck L, Vanderschueren S, Knockaert D, Mortelmans L, Bobbaers H. Repetitive 18-fluorodeoxyglucose positron emission tomography in isolated polymyalgia rheumatica: a prospective study in 35 patients. Rheumatology (Oxford) 2007;46(4). https://doi.org/10.1093/rheumatology/kel376.

[21] Weyand CM, Hicok KC, Hunder GG, Goronzy JJ. Tissue cytokine patterns in patients with polymyalgia rheumatica and giant cell arteritis. Ann Intern Med 1994;121:484-91. https://doi.org/10.7326/0003-4819-121-7-199410010-00003.

[22] Narváez J, Nolla-Solé JM, Clavaguera MT, Valverde-García J, Roig-Escofet D. Temporal arteritis and polymyalgia rheumatica in North-Eastern Spain: clinical spectrum and relationship over a 15 year period. Jt Bone Spine 2003;70:33-9. https://doi.org/10.1016/S1297-319X(02)00007-6.

[23] Liozon E, De Boysson H, Dalmay F, Gondran G, Bezanahary H, Fauchais AL, et al. Development of giant cell arteritis after treating polymyalgia or peripheral arthritis: a retrospective case-control study. J Rheumatol 2018;45:678-85. https:// doi.org/10.3899/jrheum.170455. 